\title{
Heritage architecture from the Colonización Antioqueña: the case of the Santamaría Theater
}

\author{
J. C. Ochoa \& H. H. Carvajal \\ Department of Construction, School of Architecture, \\ Universidad Nacional de Colombia, Colombia
}

\begin{abstract}
The Colonización Antioqueña was an internal migratory movement which had serious social and economic consequences for Colombia. It also strengthened many cultural expressions of the eastern part of the Country. Local, traditional and popular construction methods easily spread through what is now the countryside of Colombia's Coffee Region. Even though this architecture has not been recognized as a significant part of the Country's cultural heritage, as this designation is usually given to monumental architecture, it is still an undeniably valuable part of the cultural landscape and a contribution to Colombia's historiography. The Santamaría Theater in the town of Jericó is a building that was originally constructed using earth and wood, with the rammed earth and wattle and daub techniques being prevalent at the time. In later years there were some structural and ornamental additions in the republican style, in which materials such as concrete and zinc were mixed. The municipality recognizes that the Santamaría Theater represents a cultural and historical point of reference for Antioquia (one of Colombia's departments), and is itself a stage that characterizes the culture of Jericó. As a result, it was declared an Asset of Cultural Interest on November 25, 2008. The building has seen various interventions, the last of which was carried out between 2011 and 2012. The aim of this intervention was to revitalize the space with equipment befitting any modern theater, and in particular to foster music, theater and dance-related cultural activities. This article presents the history and description of the building while emphasizing the ground systems employed and the rehabilitation
\end{abstract}


techniques that were used to guarantee the stability and conservation of the rammed earth and wattle and daub walls.

Keywords: earth construction, rammed earth, wattle and daub, built heritage reuse, heritage conservation, adaptative reuse, cultural heritage, earth plaster, earth vernacular architecture.

\section{Introduction}

The independence of Colombia from Spain brought about great political, economic, social and cultural changes. One of these changes was the “Colonización Antioqueña” or “Antioquian Colonization”, a migratory flow which created new urban settlements in the Department of Antioquia and in the south of the Country. The municipality of Jericó was part of this process and, as a result, absorbed the customs and styles of countries such as England, France and the United States, as this society-in-the-making copied those elements.

According to the architect and historian Silvia Arango [1], the materials used are what makes the architecture from the Antioquian colonization so peculiar. The architecture basically uses wood and wattle and daub walls. The materials used, mainly earth, could be justified by low costs, the availability of the base material and the comfort conditions that they bring.

Architecture using earth is known as vernacular, traditional or popular architecture. As in many other parts of the world, this architecture has not been strictly considered heritage worth restoring. The Declaration of Amsterdam (1975) included, for the first time, allusions to the so-called "lesser architecture", extending its coverage to the vernacular and popular, as well as industrial heritage. The Declaration of Toledo (1985) emphasized the problems regarding the conservation of historical centers and, by extension, the anonymous architecture that makes them up. The Declaration of Mexico (1999) touched on the relationship between heritage and cultural tourism, emphasizing on sustainable management issues. Finally the Declaration of Krakow (2000) has brought attention to the richness of cultural diversity, the plurality of fundamental values and the importance of understanding and preserving traditional crafting and construction techniques. UNESCO, in turn, has sponsored the Declaration of Vernacular Heritage, which was ratified in Mexico by the XII General Assembly of ICOMOS (1999), and is an approximation of the nature of these types of asset [2].

For Maldonado and Vela-Cossío [2] traditional architecture joins a series of very special characteristics which mark it out and distinguish it from other forms of architecture. Among these we find the importance of convenience and functionality, sometimes to the detriment of other aesthetic and composite considerations that nevertheless tend to manifest themselves involuntarily. Moreover traditional construction techniques often demonstrate the best and most efficient use possible of building materials, techniques and construction systems. Said techniques also have an attitude in which means economy and sustainability prevail over other factors that nonetheless characterize monumental or stylish architecture. The respect for the natural world and its 
balance or, if you will, the integration of architecture into a particular cultural landscape that gives meaning to the buildings is another factor that best defines these types of edifices. Another very important trait is the clarity and rotundity with which all the auxiliary and secondary elements of this architecture express themselves in a defined way. Furthermore, the economy of the planning and construction of traditional buildings is remarkable, since such buildings are surely durable and do not require imported materials or any specialized labor other than the traditional workers. One way of expressing all these characteristics together could be that this is architecture without architects.

\section{Restoration of the Santamaría Theater in Jericó (Antioquia): stage one}

The first stage in the restoration of the Santamaría Theater began in 2011 and ended in 2012. The restoration was the responsibility of the Fundación Ferrocarril de Antioquia (Antioquian Railway Foundation) and any adjustments to the intervention proposal and inventory were made by the Projects Laboratory of the School of Architecture of Universidad Nacional de Colombia - Medellín Campus. Some of the analyses and studies that are used here were obtained from the proposal put forward by architect and restoration expert María Isabel Velásquez in 2007. However, many of them were reinterpreted and adapted to the property's new conservation status and, above all, to the country's existing legislation.

\subsection{History}

The municipality of Jericó is located in the mountainous region of southeastern Antioquia (coordinates $5^{\circ} 47^{\prime}$ north and $75^{\circ} 47^{\prime}$ west), to the left of the Cauca river and between the mouths of the Arquía and San Juan de Andes rivers. The municipality has an area of approximately $197 \mathrm{~km}^{2}$ and a population of 18,000. Additionally, it is located 113 kilometers from Medellín, the capital of the Department of Antioquia. The average year-round temperature is $18^{\circ} \mathrm{C}$, and its infrastructure is built primarily on agriculture and livestock. In recent years, and owing to the efforts in the restoration and conservation of its architectural heritage and cultural landscape, it has become one of the most touristic municipalities in the Department.

In his book entitled "The Architecture of the Colonization of Antioquia" [3], researcher Nestor Tobón Botero claims that the exact date of the founding of Jericó is unknown, but that the first colonies were established there around 1840. In that year and with the help of farmers who had emigrated from all over Antioquia, Santiago Santamaría began the colonization of the area.

On September 281850 the Provincial Chamber of Antioquia issued ordinance 15, thus creating "the village of Piedras, in the Nueva Caramanta territory”. Jericó quickly grew until, after 25 years, it became the capital of the Department; in 1857 it became a parish; in 1859 a civil settlement and, by law, in 1867 it was given the title of district. Later, Act 50 of 1877, which split the State of 
Antioquia into nine departments, designated Jericó as the capital of the state bearing the same name, on the condition that it remained that way until the beginning of the 20th century.

In the book "National Monuments of Colombia", edited by the Instituto Colombiano de Cultura (Colombian Institute of Culture) in [4], part of the urban area is recognized as being of historical interest. The outline of the urban area accurately follows the design of the orthogonal grid, with straight streets and square blocks, clearly guided by the Indian Laws on very adverse topographies. The main square assumes the title of geographical and spiritual center, housing the church and civil buildings, as well as the residences of various important citizens. Today these buildings are home to the town's main businesses.

The history of the Santamaría Theater has been obtained and updated using the research of the restorationist architect María Isabel Velásquez [5], and is shown in Table 1.

\subsection{Description}

The theater is located on a corner, and its address is: Carrera $5(25.89 \mathrm{~m})$ with Calle 9 (37.30m irregular). Carrera and Calle are terms referring to the Colombian street nomenclature. The constructed area on the first floor is $901.01 \mathrm{~m}^{2}$, and $566.05 \mathrm{~m}^{2}$ on the second floor. According to the historical study carried out by architect María Isabel Velásquez, the topology of a theater on a corner allows for a perimeter volume to be located in the theater hall. This has other administrative or commercial uses, and benefits from aeration and direct illumination, as well as serving as an insulator (see Fig. 1(a)).

In the Santamaría Theater this volume coincides with the entire lounge and forms the urban parament with streets Carrera 5 and Calle 9. The theater has two levels. There are two spaces on the first level bordering Carrera 5: the first is the access hall leading to the stalls and box seats from the 1st and 2nd levels, which also doubles as a lounge area or foyer and houses the ticket office. The second space is independent and has three access doors leading to Carrera 5 and one leading to Calle 9. There are 5 interconnected spaces bordering Calle 9. One of these gives access to the second level of the perimeter volume and another one leads to the stage. The height of the different spaces decreases as one moves away from Carrera 5, as Calle 9 is a slope which rises up to Carrera 4 (Fig. 1(b)).

There is one solitary space on the second level, which borders Carrera 5, which is illuminated by seven false balconies and can be accessed by an interior pass which is connected by staircase to Calle 9. There are four service areas of varying dimensions on the second level, bordering Calle 9, which are illuminated by false balconies. Access to these spaces is through an internal pass parallel to the theater hall, which is in turn connected to Calle 9 by staircase (see Fig. 1(c)).

The theater hall is made up of the stalls, the stage along with the prompter's box, the boxes and the balcony, where the projection room is also located. The stalls have a seated capacity of approximately 248 and two spaces for persons with reduced mobility. The boxes rise to an approximate height of $1.4 \mathrm{~m}$ and have a capacity of around 74 seats. The theater is from the republican era, characterized by a selection of architectural features such as: neoclassical 
Table 1: Chronological history of the Jericó Santamaría Theater.

\begin{tabular}{|c|c|}
\hline 1855 & Construction of the Town Hall begins \\
\hline 1856 & The Town Hall is finished \\
\hline 1866 & $\begin{array}{l}\text { The first classroom for the town's first school is inaugurated on } \\
\text { September } 1^{\text {st }}\end{array}$ \\
\hline 1877 & The building is partly destroyed by the government \\
\hline 1886 & The building is rebuilt with 7 rammed earth walls \\
\hline 1891 & The building is finished completely \\
\hline 1908 & The first cinematic projection is made on December $3^{\text {rd }}$ \\
\hline 1910 & One of the rammed earth walls falls down, killing a student \\
\hline 1914 & The stage at the children's school is built \\
\hline 1916 & $\begin{array}{l}\text { The Bank of Jericó loans } 160 \text { pesos to purchase the } \\
\text { cinematograph }\end{array}$ \\
\hline 1920 & $\begin{array}{l}\text { School activities are moved to the Escuela Modelo (Model } \\
\text { School) }\end{array}$ \\
\hline 1929 & $\begin{array}{l}\text { Part of the house is given to the Sociedad de Mejoras Públicas } \\
\text { (Society for Public Improvements) so that the school can be } \\
\text { refurbished }\end{array}$ \\
\hline 1930 & $\begin{array}{l}\text { The Sociedad de Mejoras Públicas begins work on the } \\
\text { refurbishment }\end{array}$ \\
\hline 1935 & Official Inauguration of the Santamaría Theater \\
\hline 1942 & $\begin{array}{l}\text { Cinematic projection and cultural events become regular } \\
\text { fixtures }\end{array}$ \\
\hline 1960 & $\begin{array}{l}\text { Further special adaptations and transformations are made to the } \\
\text { theater }\end{array}$ \\
\hline 1996 & Official closing of the Santamaría Theater \\
\hline 1997-1999 & $\begin{array}{l}\text { The theater is used by the Institución Universitaria Politécnico } \\
\text { Jaime Isaza Cadavid (Jaime Isaza Cadavid Polytechnic } \\
\text { University) }\end{array}$ \\
\hline 2004 & $\begin{array}{l}\text { The Casa de la Cultura (House of Culture) restores cinematic } \\
\text { projections to the theater }\end{array}$ \\
\hline 2005 & $\begin{array}{l}\text { The restoration project is approved by the Government of the } \\
\text { Department of Antioquia and preliminary studies begin }\end{array}$ \\
\hline $2006-2007$ & "First aid" work is carried out at the theater \\
\hline 2007 & $\begin{array}{l}\text { Restoration architect María Isabel Velásquez makes a new } \\
\text { proposal for intervention for the theater }\end{array}$ \\
\hline $2011-2012$ & $\begin{array}{l}\text { The School of Architecture of The Universidad Nacional de } \\
\text { Colombia - Medellín Campus carries out the adjustments to the } \\
\text { restoration proposal, and the Fundación Ferrocarril de Antioquia } \\
\text { begins work on the restoration. }\end{array}$ \\
\hline 2013 & $\begin{array}{l}\text { The second stage of the renovation process is started by the } \\
\text { Colombian Ministry of Culture. }\end{array}$ \\
\hline
\end{tabular}



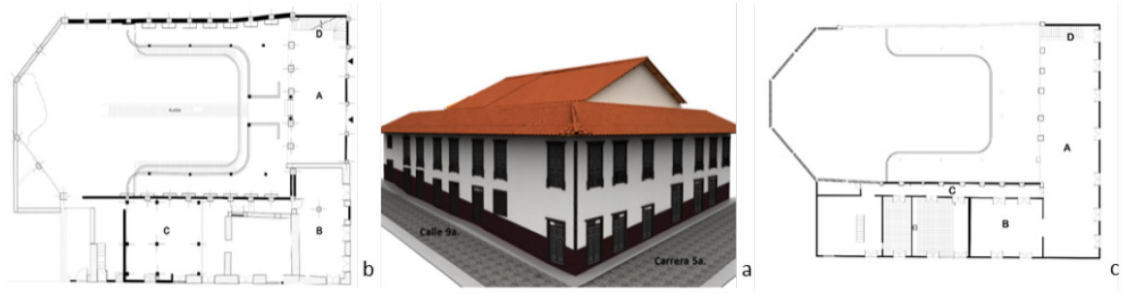

Figure 1: $\quad$ (a) Facades; (b) 1st Floor plan; (c) 2nd Floor plan.

elements in the entrance to the hall, large wooden trusses and zinc tiles as a covering; the amphitheater support structures are made from reinforced concrete with curved capitals; the curved railings on the boxes on the first floor are made from masonry and those on the second floor are made from wood and plaster. Likewise, the theater has trim moulding on the walls, dropped ceilings, multicolored painted wood and walls and floors with decorated cement tiles. Nevertheless, there are some colonial designs that have endured, such as the Spanish clay tile covering and the wooden eaves, windows and doors; all a product of the transition from Hispanic to republican.

Muñoz [6] asserts that, although the architectural and construction traditions applied in the colonization of Antioquia used rammed earth as the main construction system and material toward the late nineteenth century, this fell into disuse given the problems caused by the intense seismic activity of the region. A new building technique therefore arose, known as temblorero, which consisted of using rammed earth walls on the first floor and wattle and daub walls on the second. The former take advantage of the load-bearing capacity, while the latter provide deformation capability when faced with stress from horizontal loads, which is generally produced by seismic activity and wind. This system, which can be seen in Fig. 2, is that which was employed in the Santamaría Theater.

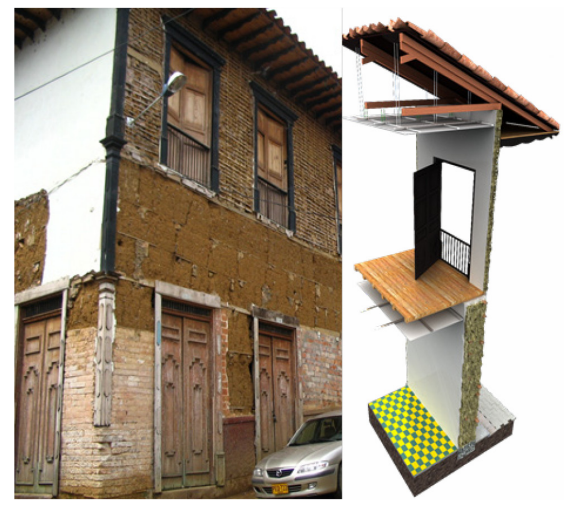

Figure 2: $\quad$ The temblorero system. 


\subsection{Restoration criteria}

The Ministry of Culture of the Republic of Colombia considers any act that brings about changes or alterations to the physical conditions of an Asset of Cultural Interest (BIC) to be an intervention (e.g. conservation, restoration, recuperation, removal, demolition, dismemberment, movement or subdivision), and takes this to mean anything from carrying out studies and designs to physical actions made to the building [7].

The following were the criteria for the intervention proposal:

- Preserve all of the main spaces within the theater hall: the stalls, boxes, stage and backstage area.

- Recondition spaces for commercial use and for services in the perimeter building.

- Relocate and redesign the sanitation systems to both improve their functionality and to meet the legal requirements with regards to quantity, access and disabled access.

- Reconfigure access to tend to the needs of the disabled.

- Reinforce the structure so that it meets the Norma Sismoresistente Colombiana (Colombian Seismoresistant Regulation), NSR 2010.

- Strengthen the construction systems for the facades. The facades of the first floor are made of rammed earth, and masonry. The facades of the second floor are made of wattle and daub.

- Protect the exterior facades from external agents using resistant plaster.

- Change the construction system of the interior for systems that are more durable, resistant and insulating, given that they have deteriorated significantly.

- Restore the wooden parts of the roofs structure. If this is not possible, then replace with wood that is in good condition.

- Guarantee that the roof is thermally and acoustically insulated.

\subsection{Restoration of the mud, rammed earth and wattle and daub walls}

The theater's perimeter building has a structural system made of rammed earth load-bearing walls on the first floor and wattle and daub walls on the second, both of which are the object of study of this paper. The plaster had started to come away from the majority of these walls, and as a result they have suffered erosion, as is the case with the rammed earth walls, as well as wood decay in the wattle and daub walls.

One of the biggest problems faced when preserving earthen systems is deciding which type of plaster to use. Old construction techniques have fallen into disuse and it is now even more difficult to find a specialist work force able to carry out the restoration. The "ready to use" industrial plaster is inadequate, and often causes harm to the earthen walls. Some researchers have attempted to study and improve the behavior of the earthen plaster used, and have proposed some potential recipes $[8,9]$. 
The interventions that have been carried out on the rammed earth walls aimed to protect the surface and the mixture itself, which had been eroded over the passage of time by weathering, thus generating a new finished surface. As well as the necessary protection for the wall, there is also refurbishment criteria for the decoration and a unifying image as an architectural enhancement [10].

Earthen plaster has two advantages: it is breathable, and its mechanical behavior is similar to that of earthen walls. This makes it more compatible than industrial plaster, which is impermeable and very rigid $[11,12]$. This mechanical compatibility can indeed be measured using the wall's and the mortar's Young modulus. If the difference between the two is large, the changes in the stresses induced on account of the variations in humidity and temperature generate a differential between the plaster and the wall. These two elements are linked and cause damage, whether it be in the mortar or in the wall. The value of Young's modulus for earthen walls (between 0.5 and $1 \mathrm{GPa}$ for the rammed earth wall) is much lower than the modulus for concrete (between 15 and $50 \mathrm{GPa}$ ). For this reason, earthen and lime/sand plaster adapt very well to earthen walls.

\subsubsection{Rammed earth walls}

The rammed earth walls used in the theater were made of raw earth mixed with sand, poured and packed into the wooden formwork. Clay is what binds the mixture together and provides resistance, although sometimes lime could have been added in small quantities in order to stabilize the mixture. The wall was constructed by superimposing modules with a height of $80 \mathrm{~cm}$ and variable lengths. Wooden boards can be seen between each module, in the whole section of the wall or only in the lateral parts (see Fig. 3(b) and Fig. 3(c)). This is surely with the aim of improving its mechanical behavior. One can also see a space left by the needle of the formwork, which was then filled with chips of ceramic material, the same as with the vertical joints.

Generally rammed earth walls show surface erosion through lack of plaster and prolonged exposure to the elements. In order to replace the surface the rammed earth wall was strengthened. This strengthening consists of restoring the original thickness of the wall with a material that is more durable and compatible than that which is currently being used. In this particular case the corners and the places for the doors and windows were strengthened using pieces of brick stuck to the rammed earth wall, which were then plastered, as can be seen in Fig. 3(c).

A mixture of lime and sand was used as plaster. The selection criterion was based on the need for a mortar on the first floor capable of resisting splashes of water and anthropic aggression. For the first layer the mixture was prepared using a ratio of 1:3; 1 part fat lime to 3 parts standard sand, and then using river sand for plaster in the second layer. The first layer of approximately $2 \mathrm{~cm}$ was applied to the surface, which had been scratched to improve adhesion. The second layer was then applied using a wooden trowel. When required, a plastic mesh with an aperture of $1 \mathrm{x} 1 \mathrm{~cm}$ was inserted between the two layers to improve adhesion, for example, between the wooden lintels and the wall, and between the mezzanine and the walls, as can be seen in Fig. 3(a). 


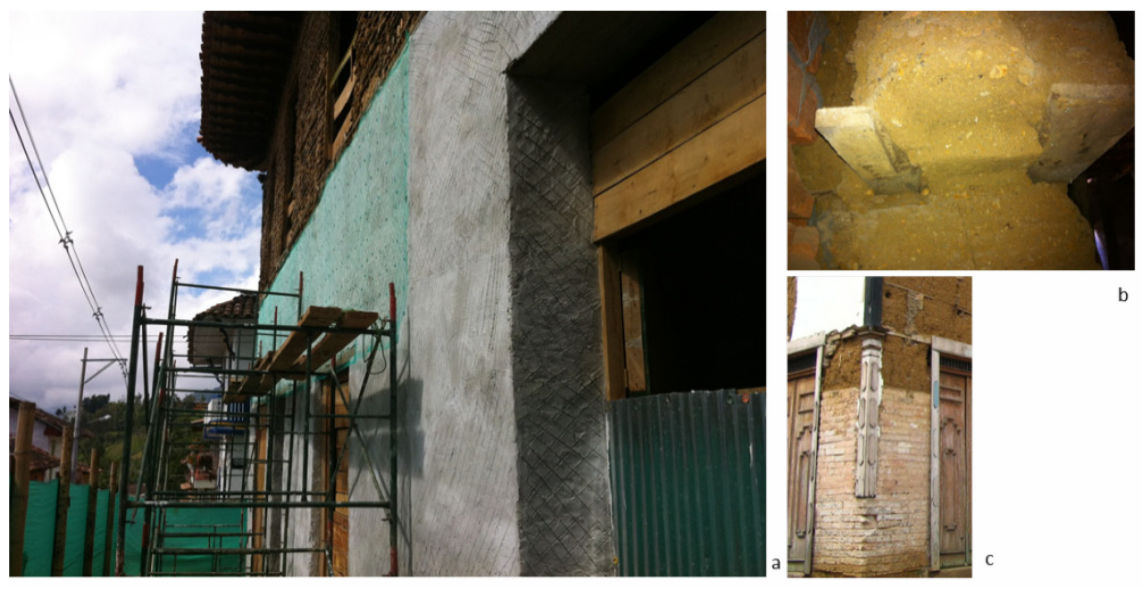

Figure 3: $\quad$ The rammed earth wall.

\subsubsection{Wattle and daub}

Wattle and daub is a mixture of earth and plants. It is characterized in Antioquia by the use of earth, collected from the region itself, as well as the combination of woods such as reeds, Guadua (both in the form of round sticks or as a matting), sawn wood and, occasionally, metal. The theater's wattle and daub walls are formed by an internal structure or frame and made from sawn wood. Two vertical structures, or right feet, two horizontal structures, or soleras, the uppermost of which is also called a carrera, as well as a brace, which is known as a diagonal make up the frame. This frame serves as a support for the wooden beams, of which there are many different types within the theater: giant reeds laid either horizontally or vertically with no space between them, bound together and without fill (see Fig. 4(a)), Guadua matting nailed to the frame without fill, (see Fig. 4(b)), giant reeds bound in a horizontal position with a space of approximately $10 \mathrm{~cm}$ between them and with earth filling between the two faces (see Fig. 4(c)); similarly there were wooden boards nailed to the frame unfilled or protecting the surface of a filled wall (see Fig. 4 (d)) . Without a doubt these different types of wattle and daub walls correspond to different construction or intervention periods.

For the intervention in the second-floor walls, all of which were made of wattle and daub, a wooden frame was used, which was then plastered with manure (cow or horse manure) while aiming to preserve the same feel of the theater. The following are the proportions that were used: 6 jars of clean manure, $13 / 4$ jars of soil, 7 handfuls of Portland cement and 5 handfuls of lime. The mixing process is traditional to the area and involves: 1) trampling the manure and the soil four times and leaving it to rest for one day; 2) adding the cement, sprinkling it over the mixture, then trampling again; 3) adding the lime, trampling again, then readying it for application. 

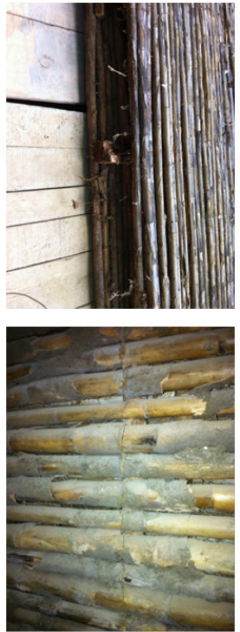

a
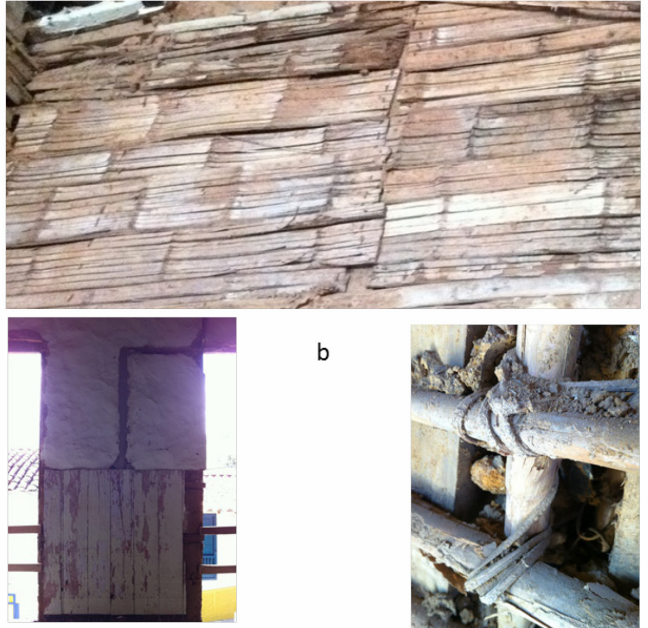

d

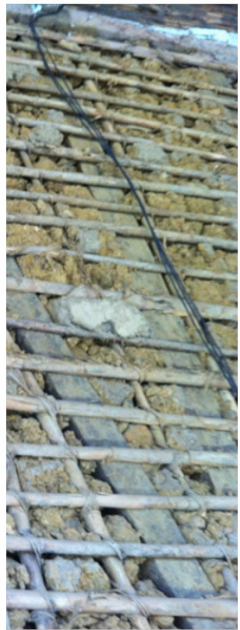

Figure 4: $\quad$ Types of wattle and daub walls.

Before applying the plaster, the wall surfaces were prepared (see Fig. 5(a)), making sure the giant reeds and wooden frame were secured. This was reinforced with a mat made of Guadua (a type of bamboo). The empty spaces in the wall were then filled with the plaster mixture and a small amount of cement dust. Moist tile pieces were used as filler. The first layer of plaster was then immediately added and cement dusted over while being careful to press the mixture in between the giant reed. It was given a rustic surface with a few deep finger marks so as to ensure the second layer sticks, and was then left to dry overnight, as can be seen in Fig. 5(b).

The second layer was applied in the same way, however this time it was spread using a trowel. Lime was then applied as an anchor so as to avoid cracks, followed finally by re-touching.

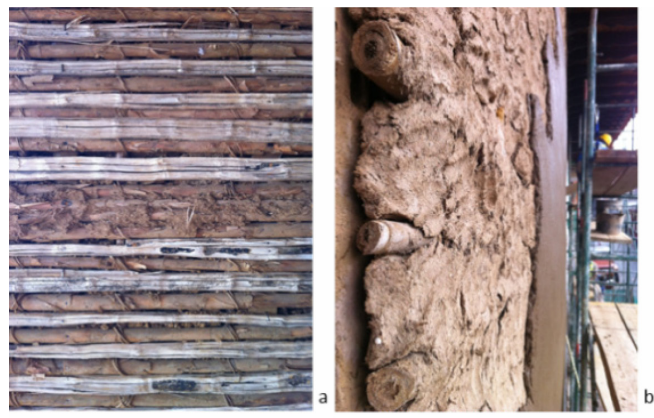

Figure 5: (a) Conditioning of the frame; (b) plaster. 


\section{Conclusions}

Restoration of popular architecture has become a challenge both for the government agencies whose duty is to preserve the Country's heritage, and for the technicians who have dedicated themselves to the search for the best materials and techniques for preserving the general principles of restoration. Such principles include conservation, sanitation, stability, reversibility, authenticity and distinctiveness. All this is done while trying to keep the intervention to a minimum.

With regards to the Santamaría Theater, all of these conditions were met, while also opening up new possibilities for researching unused materials. The originality and quality of the plaster continues to be a research problem since the improvement of the physical and mechanical properties is still a topic of interest, as the goal is that they can be used without concern and with a guarantee that they will work in other buildings with the same characteristics.

The knowledge associated with the production and application of earth and manure plaster for rammed earth and for wattle and daub walls has slowly been disappearing. The workforce skilled in this trade is becoming increasingly scarce and the production technique continues to be empirical. Although there is indeed a great deal of research on sand and lime plaster, as well as on other types of plaster which are part of Colombian heritage, manure plaster has received little study and requires further study in order to guarantee durability.

\section{References}

[1] Arango, S. Historia de la arquitectura en Colombia. Universidad Nacional de Colombia Sede Bogotá: Colombia, 1989.

[2] Maldonado, L., and Vela-Cossío, F. El patrimonio arquitectónico construido con tierra. Las aportaciones historiográficas y el reconocimiento de sus valores en el contexto de la arquitectura popular española. Informes de la Construcción. 63(523), pp. 71-80, 2011.

[3] Tobón, N. Arquitectura de la colonización antioqueña, Fondo de Cultura Cafetero: Colombia, 1987.

[4] Patiño, M. Monumentos nacionales de Colombia, Instituto Colombiano de Cultura: Colombia, 1985.

[5] Velásquez, M. I. Investigación Histórica Teatro Santamaría de Jericó (Antioquia), Particular, Estudio de Restauración: Colombia, 2007.

[6] Muñoz, J. F. Tipificación de los sistemas constructivos patrimoniales de "Bahereque" en el paisaje cultural cafetero de Colombia, Universidad Nacional de Colombia Sede Manizales: Colombia, 2010.

[7] Castellanos, V.G., Patrimonio cultural para todos: una guía de fácil comprensión. Ministerio de Cultura: Bogotá, 2010.

[8] Hamard, E., Morel, J.-C., Salgado, F., Marcom, A., and Meunier, N. A procedure to assess the suitability of plaster to protect vernacular earthen architecture. Proc. of XIIth Int. Conf, on Structural Studies, Repairs and 
Maintenance of Heritage Architecture, eds. C.A. Brebbia and L. Binda, WIT Press: UK, pp. 507-18, 2011.

[9] Elsen, J. Microscopy of historic mortars - a review, Cement and Concrete Research, 36(8), pp. 1416-24, 2006.

[10] Mileto, C., Vegas, F. and López, J. M. Criterios y técnicas de intervención en tapia. La restauración de la torre Bofilla de Bétera (Valencia), Informes de la Construcción, 63(523), pp. 81-96, 2011.

[11] Lanas, J. and Alvarez-Galindo, J. I. Masonry repair lime-based mortars: factors affecting the mechanical behavior, Cement and Concrete Research, 33(11), pp. 1867-76, 2003.

[12] Walker, P., Keable, R., Marton, J. and Maniatidis, V. Rammed Earth: Design and Construction Guidelines. IHS - BRE Press: UK, 2010. 